in vivo $34: 3047-3053(2020)$

doi:10.21873/invivo.12139

\title{
Lockdown of Breast Cancer Screening for COVID-19: Possible Scenario
}

\author{
GIANLUCA VANNI ${ }^{1}$, MARCO PELLICCIARO ${ }^{1}$, MARCO MATERAZZO $^{1}$, VALENTINA BRUNO ${ }^{2}$, \\ CHIARA OLDANI ${ }^{3}$, CHIARA ADRIANA PISTOLESE ${ }^{4}$, CHIARA BUONOMO ${ }^{5}$, \\ JONATHAN CASPI ${ }^{1}$, PAOLA GUALTIERI ${ }^{6}$, AGOSTINO CHIARAVALLOTI ${ }^{6,7}$, \\ LEONARDO PALOMBI ${ }^{6}$, EMILIO PICCIONE ${ }^{2}$ and ORESTE CLAUDIO BUONOMO ${ }^{1}$ \\ ${ }^{1}$ Breast Unit, Department of Surgical Science, Policlinico Tor Vergata University, Rome, Italy; \\ ${ }^{2}$ Section of Gynecology, Department of Surgical Science, Policlinico Tor Vergata University, Rome, Italy; \\ ${ }^{3}$ Department of Economics and Engineering, University of Viterbo 'La Tuscia', Viterbo, Italy; \\ ${ }^{4}$ Department of Diagnostic Imaging and Interventional Radiology, Molecular \\ Imaging and Radiotherapy Policlinico Tor Vergata University, Rome, Italy; \\ ${ }^{5}$ Department of Emergency and Admission, Critical Care Medicine, Pain \\ Medicine and Anesthetic Science, Policlinico Tor Vergata University, Rome, Italy; \\ ${ }^{6}$ Department of Biomedicine and Prevention, Policlinico Tor Vergata University, Rome, Italy; \\ ${ }^{7}$ IRCCS Neuromed, UOC Medicina Nucleare, Pozzilli, Italy
}

\begin{abstract}
Background/Aim: Coronavirus disease is spreading worldwide. Due to fast transmission and high fatality rate drastic emergency restrictions were issued. During the lockdown, only urgent medical services are guaranteed. All non-urgent services, as breast cancer (BC) screening, are temporarily suspended. The potential of breast cancer screening programs in increasing the survival rate and decreasing the mortality rate has been widely confirmed. Suspension could lead to worse outcomes for breast cancer patients. Our study aimed to analyse the data and provide estimates regarding the temporary $B C$ screening suspension. Patients and Methods: Data regarding breast cancer and respective screening programs were achieved through literature research and analysis. Results: Considering three different scenarios with respect to the lockdown's impact on breast cancer screening, we estimate that approximately 10,000 patients could have a missed diagnosis during these 3 months. Considering a 6-month period, as suggested by the
\end{abstract}

This article is freely accessible online.

Correspondence to: Marco Pellicciaro, Breast Unit, Department of Surgical Science, PTV: Policlinico Tor Vergata University, Viale Oxford 81, 00133 Rome, Italy. Tel: +39 3280221779, e-mail: marcopell62@gmail.com

Key Words: COVID-19, breast cancer, SARS-SOV-2, breast cancer screening, mammography, early diagnosis, local advanced diagnosis.
Imperial college model, the number of patients who will not receive a diagnosis will rise to 16,000. Conclusion: Breast cancer screening should be resumed as soon as possible in order to avoid further breast cancer missed diagnosis and reduce the impact of delayed diagnosis.

The Coronavirus disease 2019 (Covid-19) pandemic is becoming incessant, having infected almost four million people worldwide (1). Based on the latest data, in Italy, more than 200,000 people are positive for SARS-COV-2 with a case fatality rate of up to $14 \%$ (2). Due to the fast human-to-human transmission and the high fatality rate, on 10 March 2020, the Italian Government, as did other countries, introduced drastic emergency restrictions. These extraordinary measures to limit viral transmission, include: cessation of most activities, quarantine and strict self-isolation (2).

Accordingly, this emergency implies a total reorganization of the Health System, including temporary resource reallocation toward COVID-19 (3). Many hospitals are turning into COVID-19 specialized medical centers. During this transition phase, only urgent medical services are guaranteed while oncological procedures are suffering a significant slowdown (3). In this regard, the Breast Unit has been strongly affected by these restrictions as well, with a potential impact on women's health and quality of life (4).

Every year, 3 million patients receive a cancer diagnosis worldwide. Breast cancer (BC) corresponds to $14 \%$ of cancer diagnoses and to $30 \%$ of cancers in women. In Italy, approximately 53,500 women receive a BC diagnosis every year (5). During the last years, there has been an improvement 
in terms of BC prognosis with a survival rate of $87 \%$ at 5 years (6). This has been made possible thanks to the empowerment of $\mathrm{BC}$ treatment and increased incidence rate of early $\mathrm{BC}$ diagnosis by virtue of the screening programs. Berry et al. used a modelling technique to assess how screening and treatment improvements contribute to the reduction in BC mortality (7). The authors estimated that around $45 \%$ of the improvement in $\mathrm{BC}$ prognosis in western countries during the past 10-20 years, may be associated with the effect of $\mathrm{BC}$ screening (considering both, organized and self-referral screening) (7). A significant benefit of screening is the ability to diagnose $\mathrm{BC}$ at earlier stages, this being a fundamental factor in reducing recurrence and increasing the survival rate $(8,9)$. Furthermore, in the epoch of programmed screening, improvements were achieved in terms of tumor size and clinical features (10).

From the second half of the 1990s, when BC screening was introduced in Italy, many studies reported an improvement of survival and a significant decrease of BC diagnosed by physical examination (palpable lesions, nipple discharged, cutis retraction, breast ulceration and mastitis carcinomatosa) $(11,12)$.

According to European guidelines, most programs in Italy invite women aged 50-69 years to undergo screening with high-quality mammography every two years. In 2019, around 5 million women were invited and $74 \%$ of them were screened (considering both organized and self-referral screening) (13).

According to data reported in the literature, $65-70 \%$ of $\mathrm{BC}$ diagnoses were determined through radiological imaging, including organized and self-referral BC screening $(10,11)$. The remaining 30-35\% are diagnosed through physical examination. Currently, only urgent imaging is available, according to Government restrictions (2). Both, organized and self-referral screening are temporarily suspended (4). The Shutdown of screening programs along elective activities and the reduction of services could restrict the evaluation to only clinical observation of lesions detected by self-breast examination. Due to the uncertainty of the outbreak's ending time and the gradual reversion to normal situation, the aim of the study was to estimate the effect of $\mathrm{BC}$ screening suspension during the lockdown.

\section{Patients and Methods}

Epidemiological data of breast cancer were achieved from the Italian cancer registry, from Istituto Superiore di Sanità (ISS) reports and GLOBOCAN $(14,15)$. Data regarding outcome and survival from AIOM and GLOBOCAN were analysed and reported. The improvement of survival and the reduction of staging presentation in breast cancer after the introduction of screening program were extrapolated by literature. Data concerning breast cancer screening were achieved from EPICENTRO PASSI (12). All the following data were compared with data reported by studies published in the literature. For estimating mean time of breast cancer, tumor doubling times were achieved through literature analysis. Two authors performed independent data researching. The aim of our study is to analyse the data and provide estimates in three different scenarios regarding the temporary $\mathrm{BC}$ screening suspension.

\section{Results}

Scenario 1. In this scenario we estimate the impact of screening suspension using a cascade of events model.

- According to AIRTUM, the cumulative risk of developing Breast cancer between the ages of 50 and 69 is $5.5 \%$, therefore around $2.7 \%$ per year.

- Conservative analysis from screening data demonstrates, albeit some variations due to geographical distribution, an incidence rate of 1.3 invasive breast cancer per 100,000 equal inhabitants among the 50-69 age group (1.4 breast cancer in situ per 1,000).

- In fact, as of 31 December 2019, 8,599,749 women of this age group were present in Italy. Therefore, an annual incidence rate of 11,180 invasive $\mathrm{K}$ cases can be estimated.

- Cancelled or delayed screenings for a minimum period of 6 months as (delays, queues, omissions).

- From a literature analysis, together with other sources, we can assume a doubling time of 152.2 days, which, by taking the same conservative approach, can be equated to the 6 months of delayed or omitted screenings $(16,17)$.

- We can, therefore, optimistically conclude that $50 \%$ of the 11,180 cases $(5,590$ or higher) will be identified with a delay of only 6 months and will exhibit an invasive $\mathrm{K}$ double in size associated with a progression from stage II to III, and that at least as many will progress from stage I to II. It can be thus estimated that $50 \%$ of T1 (43.95\%), or about 6,000 people, would progress to T2 and about 600 from $\mathrm{T} 2$ to $\mathrm{T} 3$.

Scenario 2. In the second scenario we estimate the impact of screening suspension considering the inability to diagnose all the not clinically evident lesions. We based this analysis on the assumption that all women with a clinically evident breast lesion can carry out the normal diagnostic path same as before the lockdown event.

- Every year in Italy, according to the Italian Cancer Registry, approximately 50,000 women receive breast cancer diagnosis.

- Following the advancement of Breast Cancer Screening programs, approximately $35 \%$ of the diagnosed lesions are palpable or clinically evident cancer. Every year approximately 32,500 diagnoses of breast cancer are achieved by screening, considering both spontaneous and programmed.

- Suspension of this diagnostic path for 3 months could lead to temporarily missing $8,125 \mathrm{BC}$ diagnoses. According to Imperial College model (18), the estimated time to stopping the spread of COVID-19 is 6 months. Thus, 
following a 6 months suspension of BC screening, the temporarily missed diagnoses could reach 16,250.

- These delayed diagnoses will lead to not only more advanced stages of disease, but also a greater increase of patients in need for diagnostic paths and treatments.

- More invasive breast surgery such as mastectomy and the need for reconstructive surgery will increase (e.g. prosthesis). The number of patients who will have to perform neoadjuvant or adjuvant therapy will increase. More health resources will be required to meet the increased demand of breast cancer diagnostic paths and treatments.

- We may observe a deterioration in the quality of life of these breast cancer patients, a worse outcome and an increase in healthcare costs.

Scenario 3. In the following scenario we estimate the impact of screening suspension considering the inability to diagnose all the not clinically evident lesions. Moreover, we have considered that around 35\% (19) of women with a clinically evident breast lesion postponed the normal diagnostic path due to anxiety of COVID-19.

Starting from Scenario 2:

- Every year in Italy, according to the Italian Cancer Registry, approximately 50,000 women receive breast cancer diagnosis.

- Approximately $35 \%$ of the diagnosed lesions are palpable or clinically evident cancer.

- Due to COVID-19 anxiety, around 30\% of patients refused breast cancer diagnostic paths and treatments.

- Additional 1,300 patients could have delayed breast cancer diagnosis and treatment, related to COVID-19 anxiety.

\section{Discussion}

The spread of COVID-19 pandemic strongly influenced people's daily life together with preventive and therapeutic procedures (20). Since each hospital visit exposes patients to COVID-19's high contagiousness, the risk/benefit ratio should be considered (21). Alongside, global emergency implied a total reorganization of the Health System: medical resources and supplies are temporary reallocated toward COVID-19 (19) and non-urgent procedures are suffering a significant slowdown (3). In this regard, Breast Units have been strongly affected by these restrictions as well and BC screening programs have been shut down, with a potential impact on women's health and quality of life (4).

Breast cancer (BC) is the most frequently diagnosed cancer $(24.2 \%)$ and the leading cause of cancer-related death $(15.0 \%)$ in women worldwide (15). The latest statistics suggest that $\mathrm{BC}$ incidence rate and related mortality are increasing all over the world, reaching approximately 3.2 million new cases per year by 2050 (22). The extent of BC and its strong impact on women's life highlight the key role of preventive measures. Five-year survival rate of BC patients is above $80 \%$ in developed countries, mainly due to early prevention and treatment (23). Screening represents an independent prognostic factor in $\mathrm{BC}$, associated with an improved survival rate and decreased loco-regional recurrence incidence. Indeed, the introduction of breast screening programs allowed to achieve both, downscaling in the clinico-pathological features of invasive BCs and reducing the impact of loco-regional and adjuvant treatments (24-26). EUSOBI (European Society of Breast Imaging) and 30 national breast radiology bodies support mammography for population-based screening which demonstrated a reduction in breast cancer mortality and treatment impact (27). The International Agency for Research on Cancer (IARC), based on 20 cohort studies and 20 case-control studies conducted in high-income countries, states that mammography screening determines a reduction in mortality of up to $40 \%$ in women aged 50-69 years. In addition, they assess that the probability of false-positive needle biopsy is $<1 \%$ per round and overdiagnosis is only $1-10 \%$ for a 20 year screening. Mortality reduction was also observed among the age groups of 40-49 and 70-74 years (28).

Some studies object to screening on the basis of overdiagnosis incidence leading to over-treatment. Moreover, they suggest that the decreased mortality rate is due to the enhancement and upgrading of therapeutic procedures (29, 30). Berry et al., using seven different models, postulate that the proportion of total reduction in BC mortality was attributed to screening from 28 to $65 \%$ (median, $46 \%$ ) while adjuvant treatment contributed the rest (7). Furthermore, EUROSCREEN working group claims that for every 1,000 women aged 50-69 who are screened, 8 receive diagnosis and treatment thanks to the screening, additional 47 women with breast cancer are treated and survive, 12 die from breast cancer, 30 undergo biopsy for benign lesions, 170 undergo further diagnostic investigations for benign lesions and 729 are reassured about the absence of breast cancer $(7,28)$. Therefore, tumour stage at diagnosis of BC still significantly impacts the overall survival, even in the current era of effective systemic therapy, highlighting how early diagnosis remains crucial (27).

Screening and breast cancer in Italy. In Italy, BC represents the first cancer diagnosis among the female population with approximately 53,000 new cases in 2019. Women aged between 50-69 years exhibit the highest incident of BC, 22,482 cases (35\%) (Table I) (5). Despite a five-year survival rate over $87 \%$, BC remains the first cause of cancer-related death among the female population in Italy (17\%), with different rates according to age (Table I) (5).

The potential of BC screening programs in increasing the survival rate and decreasing the mortality rate has been widely confirmed. Mortality rate among women aged 50-69 was 
Table I. Breast cancer incidence, mortality and 5-year survival rates divided by age in Italy.

\begin{tabular}{lccc}
\hline Italy & $\begin{array}{c}\text { Incidence } \\
\text { rate }\end{array}$ & $\begin{array}{c}\text { Mortality } \\
\text { rate }\end{array}$ & $\begin{array}{c}\text { Survival rate } \\
(5 \text { years })\end{array}$ \\
\hline 40-49 years & $13,372(40 \%)$ & $28 \%$ & $91 \%$ \\
50-69 years & $22,482(35 \%)$ & $21 \%$ & $90 \%$ \\
over 70 years & $19,016(22 \%)$ & $14 \%$ & $79 \%$ \\
\hline
\end{tabular}

Incidence, mortality and survival of breast cancer according to age.

evaluated by AIRC (Foundation for Cancer Research) working group at $23 \%$ for each woman invited to a screening program (both, those who participated and those who did not) and 40\% for women who do not undergo mammography screening (31). Moreover, since the introduction of $\mathrm{BC}$ screening, the incidence of T2-T4 cancers has decreased by $30 \%$ in less than 8 years, with a steady trend over this period (6).

According to our estimate, we may observe an increase in size and stage of BC presentation, which could lead to an increase in more invasive surgeries and in the consequent need for further surgeries for breast reconstruction (32-34). Furthermore, advanced stages could require adjuvant and neoadjuvant treatments that could have been avoided. All this would lead to a deterioration in patients' quality of life and an increase in healthcare costs (35-37).

Latest data reported that out of $8,599,794$ women (target female population aged 50-69 years), $54.6 \%$ were invited to screening programs. Out of which 55\% underwent mammography screening (12). Among examined women (53.8\%), 6.2\% underwent further diagnostic investigations (Table II) (38). An additional 1,846,139 women (19.3\% of the female target population) underwent preventive mammography outside the organized programs (Table III) (12). Despite the NHS investing many resources to promote BC screening, adherence varies between the north and south of Italy: organized programs capture just over $1 / 3$ of the female target population in the southern regions, while reaching $2 / 3$ in the northern regions (Figure 1) (12).

The Italian Association of Medical Oncology (AIOM) recommends $\mathrm{BC}$ screening with a reasonable life expectancy and states that there is no age threshold for patients to suggest that breast imaging should be suspended (31). Temporary screening suspension may result in a delay in diagnosis. In addition to the negative impact in terms of cancer outcomes, this could compromise waiting lists. Indeed, these delayed and misdiagnoses could accumulate with an impact on waiting times for screening. Furthermore, the consequent increase in diagnosis could cause an increase in surgical waiting lists already slowed down by the lockdown and COVID19 anxiety of patients (19).
Table II. Organized breast cancer screening in Italy.

\begin{tabular}{lc}
\hline Organized screening (50-69 years) & \\
\hline Population & $8,599,794$ \\
Invited & $3,340,407(54.6 \%)$ \\
Undergoing & $1,846,139(55 \%)$ \\
Examined & $1,795,708(53.8 \%)$ \\
Further diagnostic investigations & $111,123(6.2 \%)$ \\
\hline
\end{tabular}

Organized breast cancer screening in Italy.

Table III. Organized and self-referral breast cancer screening in Italy.

\begin{tabular}{lc}
\hline Screening $(50-69$ years $)$ & \\
\hline Total & $74.3 \%$ IC $(73.6 ; 75)$ \\
Organizes & $54.6 \%$ IC $(53.9 ; 55.3)$ \\
Self-referral & $19.3 \%$ IC $(18.7 ; 20)$ \\
\hline
\end{tabular}

Organized and self-referral breast cancer screening.

In our opinion, the National Health care system should take any measures in order to prevent the COVID-19 detrimental effect on $\mathrm{BC}(3,4)$. BC centers changed their clinical practice to reduce hospitalization $(32,40-43)$ and immunological impact of surgical treatment $(36,44)$. During the COVID pandemic several facilities implemented or created tele-health programs for breast patients (20).

As reported by Giunti et al., several breast cancer-focused apps has been developed with some advertising complementary medicine (45). In our opinion, the National Health system should promote, through a dedicated software application, remote screening and outpatient visits to guarantee evidence-based prevention and treatment of breast cancer. These platforms could provide easier access to the Health system for patients, reduce costs in hospitals and in screening or follow-up programs. Moreover, personalized screening programs could be used temporarily in order to triage urgent patients (3). A personalized screening program already demonstrated effectiveness in terms of incremental cost-effectiveness ratio (ICER) and Quality Adjusted Life Years (QALY) and their application during outbreaks could reduce their effect on Women Health (46).

\section{Conclusion}

In our view, screening should be resumed as soon as possible, investing more resources in order to avoid further delays, since early diagnosis is a key point for breast cancer. An organized tele-health could reduce the impact of new pandemic or any new emerging stress. The COVID-19 

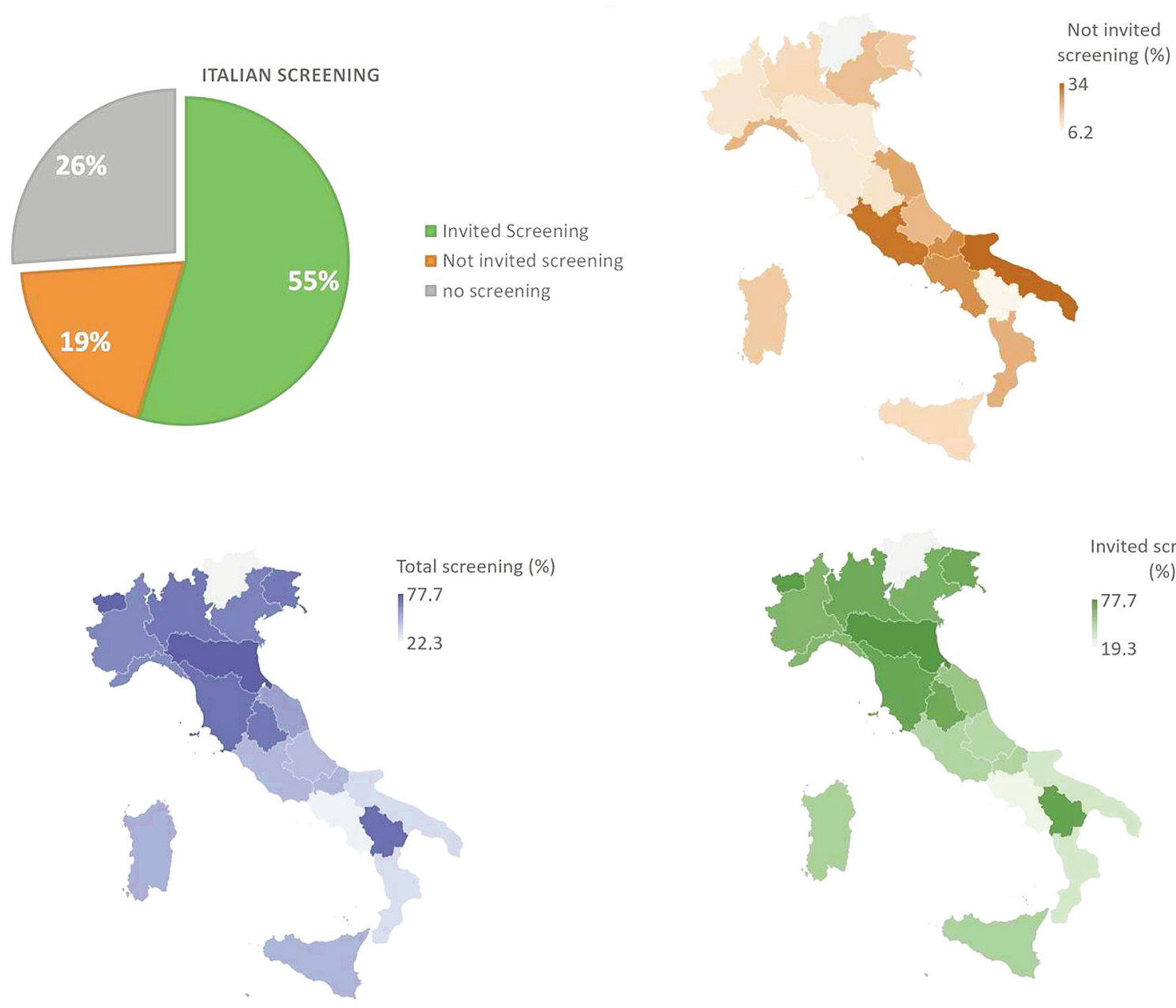

Figure 1. Organized and self-referral BC screening in Italy.

pandemic and the Sierra Leone Ebola outbreak highlighted the need for a modern, flexible national health system that has to overcome new emerging challenges that further emerging pandemic could generate $(47,48)$.

\section{Conflicts of Interest}

The Authors declare no conflicts of interest regarding this study.

\section{Authors' Contributions}

Study conception and design: Vanni Gianluca, Leonardo Palombi, Pellicciaro Marco, Materazzo Marco, Buonomo Oreste Claudio; Collection and analysis of data: Pellicciaro Marco, Materazzo Marco; Interpretation of data: Vanni Gianluca, Leonardo Palombi, Oldani Chiara, Chiaravalloti Agostistino; Figure Article draft: Marco Pellicciaro, Gianluca Vanni, Caspi Jonathan; Critical revision and draft approval: Gianluca Vanni, Marco Pellicciaro, Marco Materazzo, Valentina Bruno, Chiara Oldani, Chiara Adriana
Pistolese, Chiara Buonomo, Jonathan Caspi, Paola Gualtieri, Agostino Chiaravalloti, Leonardo Palombi, Emilio Piccione, Oreste Claudio Buonomo.

\section{Acknowledgements}

This study was found with the non-conditional contribution of the Italian Ministry of Health.

\section{References}

1 Situation Report-60 Situation in Numbers total (new) cases in last 24 hours WHO Risk Assessment Global Level Very High. Available at: https://www.who.int/docs/default-source/coronaviruse/situationreports/20200320-sitrep-60-covid-19.pdf?sfvrsn=8894045a_2 [Last accessed March 21, 2020]

2 Ministry of Health: Covid-19 - Situazione in Italia. Available at: http://www.salute.gov.it/portale/nuovocoronavirus/dettaglioConte nutiNuovoCoronavirus.jsp?lingua $=$ italiano $\&$ id $=5351 \&$ area $=$ nuov oCoronavirus\&menu=vuoto [Last accessed March 21, 2020] 
3 Buonomo OC, Materazzo M, Pellicciaro M, Caspi J, Piccione E and Vanni G: Tor Vergata University-Hospital in the beginning of COVID-19-Era: Experience and recommendation for breast cancer patients. In Vivo 34: 1661-1665, 2020. PMID: 32503826. DOI: 10.21873 /invivo. 11958

4 Vanni G, Pellicciaro M, Materazzo M, Palombi L and Buonomo OC: Breast Cancer diagnosis in coronavirus-era: Alert from Italy. Front Oncol 10: 938, 2020. DOI: 10.3389/fonc.2020.00938

5 Associazione Italiana Oncologia Medica: I Numeri del Cancro in Italia 2019. Available at: https://www.aiom.it/wpcontent/uploads/2019/09/2019_Numeri_Cancro-operatoriweb.pdf [Last accessed October 24, 2019]

6 Foca F, Mancini S, Bucchi L, Puliti D, Zappa M, Naldoni C, Falcini F, Gambino ML, Piffer S, Sanoja Gonzalez ME, Stracci F, Zorzi M and Paci E: Decreasing incidence of late-stage breast cancer after the introduction of organized mammography screening in Italy. Cancer 119: 2022-2028, 2013. PMID: 23504860. DOI: $10.1002 /$ cncr.28014.

7 Berry DA, Cronin KA, Plevritis SK, Fryback DG, Clarke L, Zelen M, Mandelblatt JS, Yakovlev AY, Habbema JDF and Feuer EJ: Effect of screening and adjuvant therapy on mortality from breast cancer. N Engl J Med 353: 1784-1792, 2005. PMID: 16251534. DOI: 10.1056/NEJMoa050518

8 Senie RT, Lesser M, Kinne DW and Rosen PP: Method of tumor detection influences disease-free survival of women with breast carcinoma. Cancer 73: 1666-1672, 1994. PMID: 8156494. DOI: $10.1002 / 1097-0142(19940315) 73: 6<1666:$ :aid cncr2820730619>3.0.co;2-e

9 Burrell HC, Pinder SE, Wilson ARM, Evans AJ, Yeoman LJ, Elston $\mathrm{CW}$ and Ellis IO: The positive predictive value of mammographic signs: A review of 425 non-palpable breast lesions. Brain Lang 51: 277-281, 1996. PMID: 8428412. DOI: 10.1016/s0009-9260(05)81207-3

10 Cedolini C, Bertozzi S, Londero AP, Bernardi S, Seriau L, Concina S, Cattin F and Risaliti A: Type of breast cancer diagnosis, screening, and survival. Clin Breast Cancer 14: 235240, 2014. PMID: 24703317. DOI: 10.1016/j.clbc.2014.02.004

11 Puliti D, Bucchi L, Mancini S, Paci E, Baracco S, Campari C, Canuti D, Cirilli C, Collina N, Conti GM, Di Felice E, Falcini F, Michiara M, Negri R, Ravaioli A, Sassoli de' Bianchi P, Serafini M, Zorzi M, Caldarella A, Cataliotti L, Zappa M, Manneschi G, Miccinesi G, Caranci N, Naldoni C, Finarelli AC, Ferretti S, Pandolfi P, Pizzi L, Petrucci C, Baldazzi P, Pasquini A, Manfredi M, Saguatti G, Zatelli M, Sgargi P, Bozzani F, Giorgi Rossi P, Mangone L, Caroli S, Vicentini M, Vattiato R, Giuliani O, Balducci C, Vitali B and Monticelli G: Advanced breast cancer rates in the epoch of service screening: The 400,000 women cohort study from Italy. Eur J Cancer 75: 109116, 2017. PMID: 28870467. DOI: 10.1016/j.ejca.2017.08.016.

12 EPICENTRO PASSI: Screening mammografico dati sorveglianza Passi. Available at: https://www.epicentro.iss.it/passi/dati/Screening Mammografico\#impatto [Last accessed April 3, 2020]

13 Sardanelli $F$ and Helbich TH: Mammography: EUSOBI recommendations for women's information. Insights Imaging 3: 710, 2012. PMID: 27854006. DOI: 10.1007/s13244-016-0531-4

14 Ferlay J, Colombet M, Soerjomataram I, Mathers C, Parkin DM, Piñeros M, Znaor A and Bray F: Estimating the global cancer incidence and mortality in 2018: GLOBOCAN sources and methods. Int J Cancer 144: 1941-1953, 2019. PMID: 30350310. DOI: $10.1002 / \mathrm{ijc} .31937$
15 Bray F, Ferlay J, Soerjomataram I, Siegel RL, Torre LA and Jemal A: Global cancer statistics 2018: GLOBOCAN estimates of incidence and mortality worldwide for 36 cancers in 185 countries. CA Cancer J Clin 68: 394-424, 2018. PMID: 30207593. DOI: $10.3322 /$ caac. 21492

16 Marzocchella L, Sini V, Buonomo O, Orlandi A, Masuelli L, Bonanno E, Lista F, Turriziani M, Manzari V, Roselli M, Modesti A and Bei R: Spontaneous immunogenicity of ribosomal $\mathrm{P} 0$ protein in patients with benign and malignant breast lesions and delay of mammary tumor growth in P0vaccinated mice. Cancer Sci 102: 509-515, 2011. PMID: 21175994. DOI: 10.1111/j.1349-7006.2010.01814.x

17 Bleicher RJ: Timing and delays in breast cancer evaluation and treatment. Ann Surg Oncol 25: 2829-2838, 2018. PMID: 29968031. DOI: $10.1245 / \mathrm{s} 10434-018-6615-2$

18 Imperial College: COVID-19 Report 13, 2020. Available at: https://www.imperial.ac.uk/mrc-global-infectious-diseaseanalysis/covid-19/ [Last accessed May 22, 2020]

19 Vanni G, Materazzo M, Pellicciaro M, Ingallinella S, Rho M, Santori F, Cotesta M, Caspi J, Makarova A, Pistolese CA and Buonomo OC: Breast cancer and COVID-19: The effect of fear on patients' decision-making process. In Vivo 34(3 suppl): 16511659, 2020. PMID: 32503825. DOI: 10.21873/invivo.11957

20 Zhao L, Zhang L, Liu JW, Yang ZF, Shen WZ and Li XR: The treatment proposal for the patients with breast diseases in the central epidemic area of 2019 coronavirus disease. Zhonghua Wai Ke Za Zhi 58: E005, 2020. PMID: 32096395. DOI: 10.3760/cma.j.cn112139-20200221-00116

21 Soran A, Gimbel M and Diego E: Breast cancer diagnosis, treatment and follow-up during COVID-19 pandemic. Eur J Breast Heal, 2020. PMID: 32285027. DOI: 10.5152/ejbh.2020.240320

22 Tao ZQ, Shi A, Lu C, Song T, Zhang Z and Zhao J: Breast Cancer: Epidemiology and Etiology. Cell Biochem Biophys 72: 333-338, 2015. PMID: 25543329. DOI: 10.1007/s12013-0140459-6

23 Sun YS, Zhao Z, Yang ZN, Xu F, Lu HJ, Zhu ZY, Shi W, Jiang J, Yao PP and Zhu HP: Risk factors and preventions of breast cancer. Int J Biol Sci 13: 1387-1397, 2017. PMID: 29209143. DOI: $10.7150 /$ ijbs. 21635

24 Cutuli B, Dalenc F, Cottu PH, Gligorov J, Guastalla JP, Petit T and Amrate A: Impact of screening on clinicopathological features and treatment for invasive breast cancer: Results of two national surveys. Cancer/Radiotherapie 19: 295-302, 2015. PMID: 26188735. DOI: 10.1016/j.canrad.2015.02.015

25 Lehtimäki $\mathrm{T}$, Lundin $\mathrm{M}$, Linder $\mathrm{N}$, Sihto $\mathrm{H}$, Holli $\mathrm{K}$, Turpeenniemi-Hujanen T, Kataja V, Isola J, Joensuu $\mathrm{H}$ and Lundin J: Long-term prognosis of breast cancer detected by mammography screening or other methods. Breast Cancer Res 13: R134, 2011. PMID: 22204661. DOI: 10.1186/bcr3080

26 Paci E, Broeders M, Hofvind S and Duffy SW: Summary of the evidence of breast cancer service screening outcomes in Europe and first estimate of the benefit and harm balance sheet. J Med Screen 19: 5-13, 2012. PMID: 22972806. DOI: 10.1258/jms.2012.012077

27 Sardanelli F, Aase HS, Álvarez M, Azavedo E, Baarslag HJ, Balleyguier C, Baltzer PA, Beslagic V, Bick U, BogdanovicStojanovic D, Briediene R, Brkljacic B, Camps Herrero J, Colin C, Cornford E, Danes J, de Geer G, Esen G, Evans A, Fuchsjaeger MH, Gilbert FJ, Graf O, Hargaden G, Helbich TH, Heywang-Köbrunner SH, Ivanov V, Jónsson Á, Kuhl CK, Lisencu EC, Luczynska E, Mann RM, Marques JC, Martincich 
L, Mortier M, Müller-Schimpfle M, Ormandi K, Panizza P, Pediconi F, Pijnappel RM, Pinker K, Rissanen T, Rotaru N, Saguatti G, Sella T, Slobodníková J, Talk M, Taourel P, Trimboli RM, Vejborg I, Vourtsis A and Forrai G: Position paper on screening for breast cancer by the European Society of Breast Imaging (EUSOBI) and 30 national breast radiology bodies from Austria, Belgium, Bosnia and Herzegovina, Bulgaria, Croatia, Czech Republic, Denmark, Estonia, Finland, France, Germany, Greece, Hungary, Iceland, Ireland, Italy, Israel, Lithuania, Moldova, The Netherlands, Norway, Poland, Portugal, Romania, Serbia, Slovakia, Spain, Sweden, Switzerland and Turkey. Eur Radiol 27: 2737-2743, 2017. PMID: 27807699. DOI: $10.1007 / \mathrm{s} 00330-016-4612-\mathrm{z}$

28 Lauby-Secretan B, Scoccianti C, Loomis D, Benbrahim-Tallaa L, Bouvard V, Bianchini F and Straif K: Breast-cancer screening - viewpoint of the IARC Working Group. N Engl J Med 372: 2353-2358, 2015. DOI: 10.1056/NEJMc1508733

29 Vedantham S, Karellas A, Vijayaraghavan GR and Kopans DB: Digital breast tomosynthesis: State of the art1. Radiology 277: 663684, 2015. PMID: 26599926. DOI: 10.1148/radiol.2015141303

30 Houssami $\mathrm{N}$ and Skaane P: Overview of the evidence on digital breast tomosynthesis in breast cancer detection. Breast 22: 101108, 2013. PMID: 23422255. DOI: 10.1016/j.breast.2013.01.017

31 Associazione Italiana di Oncologia Medica: Linee guida Neoplasie della Mammella, 2019. Available at: https://www.aiom.it/wpcontent/uploads/2019/10/2019_LG_AIOM_Mammella.pdf [Last accessed June 18, 2020]

32 Calì Cassi L, Biffoli F, Francesconi D, Petrella G and Buonomo $\mathrm{O}$ : Anesthesia and analgesia in breast surgery: the benefits of peripheral nerve block. Eur Rev Med Pharmacol Sci 21: 13411345, 2017. PMID: 28387892.

33 Calì Cassi L, Vanni G, Petrella G, Orsaria P, Pistolese C, Lo Russo G, Innocenti M and Buonomo O: Comparative study of oncoplastic versus non-oncoplastic breast conserving surgery in a group of 211 breast cancer patients. Eur Rev Med Pharmacol Sci 20: 2950-2954, 2016. PMID: 27460720.

34 Bielli A, Bernardini R, Varvaras D, Rossi P, Di Blasi G, Petrella G, Buonomo OC, Mattei M and Orlandi A: Characterization of a new decellularized bovine pericardial biological mesh: Structural and mechanical properties. J Mech Behav Biomed Mater 78: 420426, 2018. PMID: 29223730. DOI: 10.1016/j.jmbbm.2017.12.003

35 Orsaria P, Varvaras D, Vanni G, Pagnani G, Scaggiante J, Frusone F, Granai AV, Petrella G and Buonomo OC: Nodal status assessment in breast cancer: Strategies of clinical grounds and quality of life implications. Int J Breast Cancer 2014: 469803, 2014. PMID: 24672730. DOI: 10.1155/2014/469803

36 Vanni G, Materazzo M, Perretta T, Meucci R, Anemona L, Buonomo C, Dauri M, Granai AV, Rho M, Ingallinella S, Tacconi F, Ambrogi V, Chiaravalloti A, Schillaci O, Petrella G and Buonomo OC: Impact of awake breast cancer surgery on postoperative lymphocyte responses. In Vivo 33: 1879-1884, 2019. PMID: 31662515. DOI: 10.21873/invivo.11681

37 Ackerman RS, Hirschi M, Alford B, Evans T, Kiluk J V and Patel SY: Enhanced revenue after surgery? A cost-standardized enhanced recovery pathway for mastectomy decreases length of stay. World J Surg 43: 839-845, 2019. PMID: 30456482. DOI: $10.1007 / \mathrm{s} 00268-018-4850-0$
38 Osservatorio Nazionale Screening: Lo screening mammografico. Available at: https://www.osservatorionazionalescreening.it/ content/screening-mammografico [Last accessed June 16, 2020]

39 World Health Organization (WHO): Solidarity clinical trial for COVID-19 treatments. Available at: https://www.who.int/ emergencies/diseases/novel-coronavirus-2019/global-research-onnovel-coronavirus-2019-ncov/solidarity-clinical-trial-for-covid-19treatments [Last accessed May 31, 2020]

40 Liu B, Ma F, Wang J, Fan Y, Mo H and Xu B: Health management of breast cancer patients outside the hospital during the outbreak of 2019 novel coronavirus disease. Zhonghua Zhong Liu Za Zhi 42: E002, 2020. PMID: 32100979. DOI: 10.3760/cma.j.cn112152-20200221-00110

41 Buonomo O, Granai A V, Felici A, Piccirillo R, De Liguori Carino N, Guadagni F, Polzoni M, Mariotti S, Cipriani C, Simonetti G, Cossu E, Schiaroli S, Altomare V, Cabassi A, Pernazza E, Casciani $\mathrm{CU}$ and Roselli M: Day-surgical management of ductal carcinoma in situ (DCIS) of the breast using wide local excision with sentinel node biopsy. Tumori 88: S48-9, 2002. PMID: 12365390. DOI: $10.1177 / 030089160208800342$

42 Buonomo O, Cabassi A, Guadagni F, Piazza A, Felici A, Piccirillo R, Atzei G, Cipriani C, Schiaroli S, Mariotti S, Guazzaroni M, Cossu E, Simonetti G, Pernazza E, Casciani C and Roselli M: Radioguided-surgery of early breast lesions. Anticancer Res 21: 2091-2097, 2001. PMID: 11501831.

43 Orsaria P, Chiaravalloti A, Fiorentini A, Pistolese C, Vanni G, Granai AV, Varvaras D, Danieli R, Schillaci O, Petrella G and Buonomo OC: PET probe-guided surgery in patients with breast cancer: Proposal for a methodological approach. In Vivo 31: 101-110, 2017. PMID: 28064227. DOI: 10.21873/invivo.11031

44 Mineo TC, Sellitri F, Vanni G, Gallina FT and Ambrogi V: Immunological and inflammatory impact of non-intubated lung metastasectomy. Int J Mol Sci 18, 2017. PMID: 28686211. DOI: 10.3390/ijms18071466

45 Giunti G, Giunta DH, Guisado-Fernandez E, Bender JL and Fernandez-Luque L: A biopsy of breast cancer mobile applications: state of the practice review. Int J Med Inform 110: 1-9, 2018. PMID: 29331247. DOI: 10.1016/j.ijmedinf.2017.10.022

46 Román M, Sala M, Domingo L, Posso M, Louro J and Castells $\mathrm{X}$ : Personalized breast cancer screening strategies: A systematic review and quality assessment. PLoS One 14: e0226352, 2019. PMID: 31841563. DOI: 10.1371/journal.pone.0226352

47 Gates B: The next epidemic - Lessons from Ebola. N Engl J Med 372: 1381-1384, 2015. PMID: 25853741. DOI: 10.1056/NEJM p1502918

48 Gates B: Responding to Covid-19 - A once-in-a-century pandemic? N Engl J Med 382: 1677-1679, 2020. PMID: 32109012. DOI: $10.1056 /$ NEJMp2003762
Received May 28, 2020

Revised June 16, 2020

Accepted June 18, 2020 